Acta Theriologica 44 (2): 161-171, 1999.

PL ISSN 0001-7051

\title{
The record of the reproductive cycle in the incisor dentine of spotted souslik Spermophilus suslicus
}

\author{
Yulia E. TRUNOVA, Vladimir A. LOBKOV \\ and Galina A. KLEVEZAL
}

Trunova Y. E., Lobkov V. A. and Klevezal G. A. 1999. The record of the reproductive cycle in the incisor dentine of spotted souslik Spermophilus suslicus. Acta Theriologica 44: $161-171$.

To examine the changes in dentine microstructure in spotted souslik Spermophilus suslicus (Güldenstaedt, 1770) during pregnancy, parturition and lactation, we investigated 39 females from the Odessa region. Thirty females were dead-trapped in March-July, 1987-1997, nine females (lactating or pregnant) were caught in April, 1996, injected with tetracycline as a time marker and kept in captivity during 14-47 days. Their litters survived from 1 to 29 days. We analyzed cross stained sections as well as cross ground sections of upper incisors. In the lactating sousliks both in nature and in captivity the daily layers formed in the course of pregnancy were followed by formation of a specific dentine pattern. The pattern consisted of alternating contrastive hypochromatic and hyperchromatic bands of about $30-50 \mu$ wide. The beginning of the pattern formation coincided approximately with parturition and the formation continued during lactation. Therefore, the parturition-lactation zone could be the correct name for the pattern. In captured females no correlation between the duration of the pattern formation and the lifespan of their litters was found. The pattern was absent in immature and barren females. We found no changes in the dentine formation during pregnancy.

Kol'tzov Institute of Developmental Biology, Russian Academy of Sciences, 26 Vavilov Str.,117808 Moscow, Russia, e-mail: trunovs@orc.ru, klevezal@glas.apc.org. (YET, GAK); Odessa-II-Mechnikov-State University, Shampanskiy pereulok, 2, 270058 Odessa Ukraine (VAL)

Key words: Spermophilus suslicus, incisor dentine, parturition, lactation

\section{Introduction}

Dentine of continuously erupting incisors is the most sensitive recording structure of mammals due to the high rate of its apposition. Daily growth rhythm of the dentine formation in rats was established more than 50 years ago (Schour and Steadman 1935). Daily layers were found in incisors of many laboratory and wild mammals (see Klevezal 1996 for a review). Ultradian layers of unclear periodicity were also described for several cases (Rosenberg and Simmons 1980, Klevezal et al. 1990, Ohtsuka and Shinoda 1995). Records of some events of animal life connected directly or indirectly with body growth and mineral metabolism were found against 
the background of these daily and ultradian layers. Winter retardation of body growth in non-hibernating rodents is recorded by decrease in daily layer width; in hibernating rodents, winter period is recorded as a special dentine pattern - the hibernation zone (Klevezal and Mina 1990, Klevezal et al. 1993, Klevezal and Sukhovskaya 1995, Trunova and Lobkov 1997). In lactating females of Spermophilus (Citellus) pygmaeus and S. undulatus, another dentine pattern, the lactation zone, was described (Klevezal and Sukhovskaya 1995), its etiology remains unclear.

The purpose of this investigation was to examine the changes in incisor dentine microstructure during pregnancy, parturition, lactation in spotted souslik Spermophilus suslicus (Güldenstaedt, 1770) and compare these changes with those in immature, barren and post-weaning ones.

\section{Material and methods}

We studied upper incisors of 39 females of Spermophilus suslicus from the Odessa region. Thirty females were dead-trapped in March-July, 1987-1997. One lactating female (Table 1 no 26) was caught by live-trap, injected with tetracycline and released; it was dead-trapped 21 days later (Table 1). Nine females were caught by live-traps in April, 1996, maintained either in a dark room (Table 2, no 1, $3-5,7-9)$ or under natural light conditions $($ no 2,6$)\left(t=+15^{\circ} \mathrm{C}\right.$, food and water ad libitum) and sacrificed (some died - no 1,3,5) in 14-47 days. These animals were pregnant when captured (except for the lactating female no 5) and gave birth in captivity 1-10 days later. Some litters died soon, others survived up to the weaning.

In the live-trapped animals the pregnancy and approximate size of embryos were established by palpation, in the dead-trapped ones maximum size of embryos was estimated after dissection.

On the first or the second day of captivity, each female received an intramuscular injection of 20 $\mathrm{mg} / \mathrm{kg}$ of tetracycline. We used tetracycline as a time marker. It is absorbed by the growing dentine within approximately half-a-day after intramuscular injection. One can see a tetracycline mark as a yellow stripe in ultraviolet light in a ground section; decalcification destroys the mark (see Klevezal 1996 for a review).

The middle portion of the upper incisor received from the animals untreated with tetracycline was decalcified, 15-20 serial cross sections $15-30 \mu$ thick were cut on a freezing microtome, stained with Ehrlich hematoxylin, mounted in glycerol and investigated under the microscope. The character of dentine in both labial (covered by enamel) and lingual (covered by cementum) walls of the incisor was analyzed.

In each animal injected with tetracycline, a thin cross ground section was cut using an Isomet low-speed saw through the middle part of the incisor and ground to a thickness of about $30 \mu$. In the ground section under ultraviolet light, we measured: (1) the distance from the edge of the pulp cavity to the dentino-enamel junction (the width of the labial wall) and (2) the distance from the edge of the pulp cavity to the tetracycline mark. The series of the stained sections were prepared from the adjacent portion of the same incisor after decalcification. We chose a stain section with the width of the labial wall equal to that in the ground section, and projected the second measurement. In this way we estimated the tetracycline mark position in relation to the dentine design that was better visible in the stained sections than in the ground ones. The change of dentine dimensions due to decalcification can be neglected because demineralization causes a small nonsignificant $(1.9 \%)$ reduction in dentine volume (Carvalho et al. 1996). In the stained section the third measurement was made to determine the distance from the edge of the pulp cavity to the beginning of the specific dentine design (pattern). To estimate the average width of daily layer the number of daily layers in $200 \mu$ of the middle part of the labial wall was calculated in 2-3 non-adjacent sections of the same incisor. All the measurements were made in the labial wall using ocular-micrometer. The error of the measurements was $\pm 10 \mu$. 


\section{Results}

The daily layers and other dentine designs are seen in all walls of the tooth, differing between the walls in contrast and in width of their elements more often than not in favour of the lingual wall. In some cases the dentine layers and other designs are not readily visible in the mantle dentine (about $20-50 \mu$ of poorly stained peripheral dentine).

\section{Females in nature}

Females, which were dead-trapped in nature, represented all stages of reproductive cycle, from immaturity up to post-weaning (Table 1). In the young-of-the year females trapped in July, the daily layers of about 18-20 $\mu$ wide were observed in the dentine. In females trapped in March, soon after arousal from hibernation, 3-4 daily layers followed the hibernation zone. In barren and in pregnant females trapped in April-May, only daily layers were seen after the hibernation zone. The latter was already shifted to the periphery of the section because of the constant eruption of the incisor (Fig. 1). The larger embryos a female had at the time of death, the more daily layers were formed after the hibernation zone in its dentine (Table 1). There were approximately 21-22 daily layers in two individuals with embryos 17-18 mm maximum, 22 daily layers in three individuals with embryos $30-35 \mathrm{~mm}$ maximum and 24-30 daily layers in three individuals with embryos 40 $\mathrm{mm}$ maximum.

In lactating females, the daily layers formed in the course of pregnancy were followed by a specific dentine design (the pattern) that stood out against a background of more or less visible daily layers (Fig. 2). The pattern consisted of alternating contrastive hypochromatic (lightly stained) bands of about 30-50 $\mu$ wide, with 2-4 daily layers each and hyperchromatic (deeply stained) ones that could vary in width and in the number of daily layers. A pair of adjacent hypochromatic and hyperchromatic bands, where the hypochromatic one was the most noticeable, was named a set. The contrast of the sets could vary from distinct to poorly visible.

The lactating female, which had been labeled with tetracycline in nature and trapped 21 days later, had the tetracycline mark inside the pattern. In lactating females trapped at the beginning of May 1987, May 1997 and June 1996, the dentine pattern included 1-4, 6-7 and 9 sets, respectively. In one lactating female trapped at the beginning of May 1997, there was no pattern described above except several slightly hyperchromatic bands among daily layers (Table 1 no 25 ).

In four females in post partum period that had both the hibernation zone and the pattern on the same section, the number of daily layers between the hibernation zone and the pattern averaged $29.0 \pm 0.94$ ( $\lim 27-32$ ), and in one female this number was $20.86 \pm 2.85$ (lim 17-25).

Four females trapped in June were already in post-reproduction period according to the state of their uterus and mammal glands; they had only regular daily 
Table 1. The dentine formation in upper incisors of females Spermophilus suslicus in nature.

\begin{tabular}{|c|c|c|c|c|}
\hline $\begin{array}{l}\text { Num- } \\
\text { ber of } \\
\text { female }\end{array}$ & $\begin{array}{c}\text { Date of } \\
\text { death }\end{array}$ & $\begin{array}{l}\text { Reproduc- } \\
\text { tive } \\
\text { phase }\end{array}$ & $\begin{array}{l}\text { Dentine configuration } \\
\text { from periphery of the section to the pulp cavity } \\
\text { (for daily layers: } \bar{x} \pm \mathrm{SD}, n=5-7 \text { ) }\end{array}$ & Notes \\
\hline 1 & 2 & 3 & 4 & 5 \\
\hline 1 & 22.06 .96 & immature & $31.6 \pm 0.89$ daily layers & young-of-the year \\
\hline 2 & 29.06 .89 & immature & $22.6 \pm 0.89$ daily layers & young-of-the year \\
\hline 3 & 12.07 .89 & immature & $32.6 \pm 0.55$ daily layers & young-of-the year \\
\hline 4 & 12.07 .89 & immature & $24.6 \pm 0.55$ daily layers & young-of-the year \\
\hline 5 & 13.03 .88 & barren & hibernation zone +4 daily layers & without embryos \\
\hline 6 & 31.03 .87 & barren & hibernation zone +4 daily layers & without embryos \\
\hline 7 & 31.03 .87 & barren & hibernation zone $+3-4$ daily layers & without embryos \\
\hline 8 & 02.05 .87 & barren & hibernation zone $+29.40 \pm 1.14$ daily layers & without embryos \\
\hline 9 & 09.05 .87 & barren & $\begin{array}{l}\text { hibernation zone }+33.17 \pm 2.23 \text { daily layers } \\
\text { with } 5-6 \text { sets of slightly contrastive } \\
\text { bands among them }\end{array}$ & without embryos \\
\hline 10 & 13.04 .96 & pregnant & hibernation zone $+21.0 \pm 0.71$ daily layers & 6 embryos (17 $\mathrm{mm} \max )$ \\
\hline 11 & 25.04 .87 & pregnant & hibernation zone $+22.0 \pm 0.71$ daily layers & 6 embryos (18 mm max) \\
\hline 12 & 07.04 .97 & pregnant & hibernation zone $+21.6 \pm 1.34$ daily layers & 6 embryos (30 mm max) \\
\hline 13 & 07.04 .97 & pregnant & hibernation zone $+22.0 \pm 1.0$ daily layers & 7 embryos (30 mm max) \\
\hline 14 & 30.03 .97 & pregnant & hibernation zone $+22.4 \pm 1.14$ daily layers & 4 embryos (35 mm max) \\
\hline 15 & 30.03 .97 & pregnant & hibernation zone $+24.2 \pm 0.84$ daily layers & 2 embryos ( $40 \mathrm{~mm} \max )$ \\
\hline 16 & 07.04 .97 & pregnant & hibernation zone $+28.2 \pm 0.84$ daily layers & 4 embryos (40 mm max) \\
\hline 17 & 07.04 .97 & pregnant & hibernation zone $+30.2 \pm 0.84$ daily layers & 9 embryos (40 mm max) \\
\hline 18 & 02.05 .87 & lactating & $\begin{array}{l}\text { hibernation zone }+29.8 \pm 0.84 \text { daily layers } \\
+ \text { the pattern ( } 1 \text { set of slightly contrastive } \\
\text { bands), } 4 \text { daily layers }\end{array}$ & $\begin{array}{l}\text { fresh placental spots } \\
\text { in uterus, milk in } \\
\text { mammal glands }\end{array}$ \\
\hline 19 & $2-9.05 .87$ & lactating & $\begin{array}{l}\text { hibernation zone }+29.8 \pm 1.48 \text { daily layers } \\
+ \text { the pattern ( } 1 \text { set of contrastive bands), } \\
8-9 \text { daily layers }\end{array}$ & $\begin{array}{l}\text { fresh placental spots } \\
\text { in uterus, milk in } \\
\text { mammal glands }\end{array}$ \\
\hline 20 & 02.05 .87 & lactating & $\begin{array}{l}\text { hibernation zone }+28.4 \pm 0.55 \text { daily layers } \\
+ \text { the pattern ( } 1 \text { set of contrastive bands), } \\
4 \text { daily layers }\end{array}$ & $\begin{array}{l}\text { fresh placental spots } \\
\text { in uterus, milk in } \\
\text { mammal glands }\end{array}$ \\
\hline 21 & 02.05 .87 & lactating & $\begin{array}{l}\text { hibernation zone }+28.0 \pm 1.22 \text { daily layers } \\
+ \text { the pattern ( } 1 \text { set of contrastive bands), } \\
4-5 \text { daily layers }\end{array}$ & $\begin{array}{l}\text { fresh placental spots } \\
\text { in uterus, milk in } \\
\text { mammal glands }\end{array}$ \\
\hline 22 & 02.05 .87 & lactating & $\begin{array}{l}\text { hibernation zone }+20.86 \pm 2.85 \text { daily layers } \\
+ \text { the pattern ( } 4 \text { sets of contrastive bands), } \\
16.6 \pm 0.55 \text { daily layers }\end{array}$ & $\begin{array}{l}\text { placental spots in uterus, } \\
\text { milk in mammal glands }\end{array}$ \\
\hline 23 & 09.05 .97 & lactating & $\begin{array}{l}\text { the pattern ( } 6-7 \text { irregular sets of slightly } \\
\text { contrastive bands), } 37.6 \pm 1.67 \text { daily layers }\end{array}$ & $\begin{array}{l}\text { placental spots in uterus, } \\
\text { milk in mammal glands }\end{array}$ \\
\hline 24 & 09.05 .97 & lactating & $\begin{array}{l}\text { the pattern ( } 6 \text { sets of slightly contrastive } \\
\text { bands), } 32.17 \pm 2.32 \text { daily layers }\end{array}$ & $\begin{array}{l}\text { placental spots in uterus, } \\
\text { milk in mammal glands }\end{array}$ \\
\hline 25 & 09.05 .97 & lactating & $\begin{array}{l}31.9 \pm 1.29 \text { daily layers with } 2-4 \\
\text { slightly contrastive hyperchromatic bands }\end{array}$ & $\begin{array}{l}\text { placental spots in uterus, } \\
\text { milk in mammal glands }\end{array}$ \\
\hline 26 & 09.06.96 & lactating & $\begin{array}{l}\text { the pattern ( } 9 \text { sets of contrastive bands), } \\
35.6 \pm 2.4 \text { daily layer }\end{array}$ & $\begin{array}{l}\text { placental spots in uterus, } \\
\text { milk in mammal glands }\end{array}$ \\
\hline
\end{tabular}


Table 1 - concluded.

\begin{tabular}{|c|c|c|c|c|}
\hline 1 & 2 & 3 & 4 & 5 \\
\hline 27 & 15.06 .89 & $\begin{array}{l}\text { post- } \\
\text {-weaning }\end{array}$ & $34.2 \pm 3.70$ daily layers & $\begin{array}{l}\text { placental spots in uterus, } \\
\text { no milk in mammal glands }\end{array}$ \\
\hline 28 & 15.06 .89 & $\begin{array}{l}\text { post- } \\
\text {-weaning }\end{array}$ & $30.4 \pm 0.89$ daily layers & $\begin{array}{l}\text { placental spots in uterus, } \\
\text { no milk in mammal glands }\end{array}$ \\
\hline 29 & 15.06 .89 & $\begin{array}{l}\text { post- } \\
\text {-weaning }\end{array}$ & $32.8 \pm 1.48$ daily layers & $\begin{array}{l}\text { placental spots in uterus, } \\
\text { no milk in mammal glands }\end{array}$ \\
\hline 30 & 15.06 .89 & $\begin{array}{l}\text { post- } \\
\text {-weaning }\end{array}$ & $31.6 \pm 1.14$ daily layers & $\begin{array}{l}\text { placental spots in uterus, } \\
\text { no milk in mammal glands }\end{array}$ \\
\hline
\end{tabular}

layers in the dentine or, in one case, the daily layers with several hypochromatic bands among them (Table 1 no 28).

We measured the width of the daily layers (in the middle of the labial wall) in 2 barren, 6 pregnant and 6 lactating females. The averages and standard deviations were $15.1 \pm 0.73,14.2 \pm 1.71$ and $15.1 \pm 1.46 \mu$, respectively. There were no significant differences between the groups.

\section{Females in captivity}

Eight captured females were pregnant and gave birth in captivity in 1-10 days (Table 2). Their litters survived 1-29 days. The specific pattern in the dentine similar to that of the lactating females from nature was seen in all individuals. Three females injected with tetracycline before parturition had the mark in the

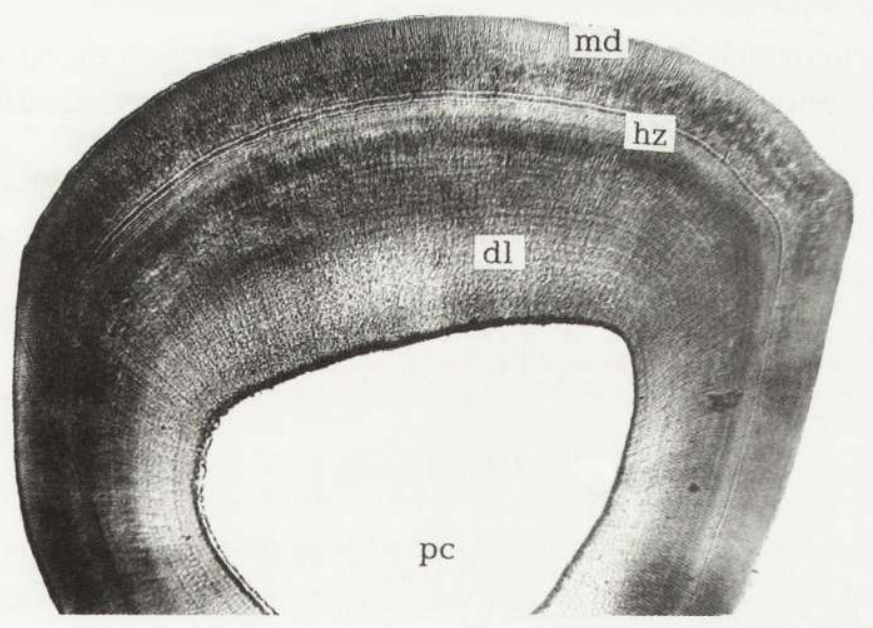

Fig. 1. Cross section through the middle part of the upper incisor of pregnant female Spermophilus suslicus (Table 1 no 14) (Ehrlich hematoxylin, ob. 6.3, oc. 3). md - mantle dentine, hz - hibernation zone, dl - daily layers, pc - pulp cavity. 


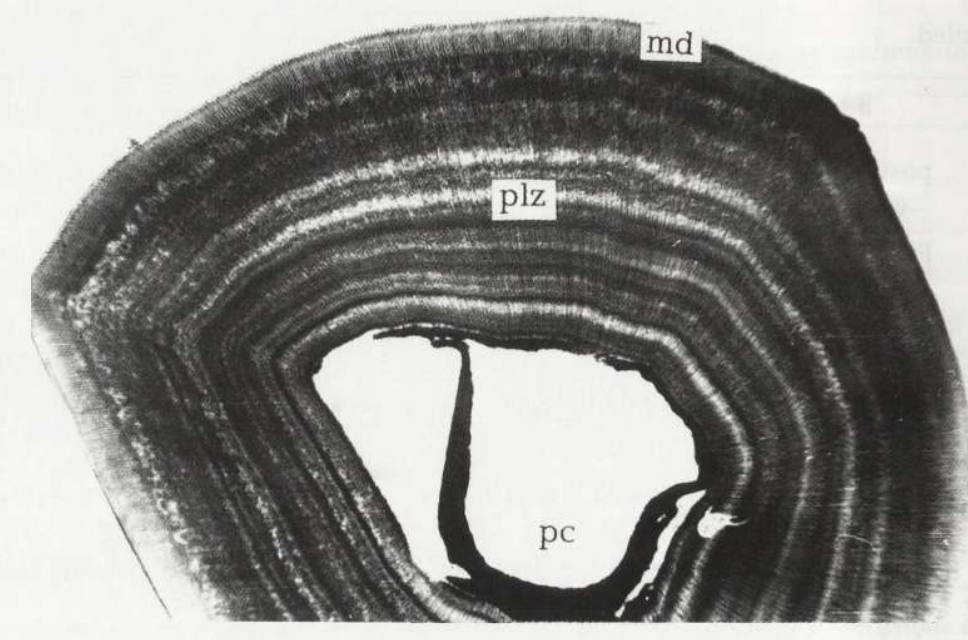

Fig. 2. Cross section through the middle part of the upper incisor of lactating female Spermophilus suslicus (Table 2 no 2) (Ehrlich hematoxylin, ob. 6.3, oc. 3). md - mantle dentine, plz - parturition-lactation zone consisting of alternating hypochromatic and hyperchromatic bands, pc - pulp cavity.

dentine in front of the pattern (Table 2 nos $1,2,3$ ). The distance between the tetracycline mark and the pattern was $40-60 \mu$ in two of them, which had parturition not later than in 3 days after the injection, and 90-110 $\mu$ in another, which gave birth in 7-10 days after the injection. One female was injected in 25-26 days after parturition, during lactation; it had the tetracycline mark inside the pattern (Table 2 no 4 ).

In the female, which was injected with tetracycline when lactating and died 14 days later, the tetracycline mark was seen in the pattern consisting of faintly discernible sets.

No correlation was found between the width of the pattern or the number of the sets and the life-span of the litters. Spearman coefficients of rank correlation were $r_{\mathrm{S}}=0.42,<r_{\mathrm{S}} 0.05$ and $r_{\mathrm{S}}=0.34,<r_{\mathrm{S}} 0.05$, respectively.

No differences in the dentine formation was found between the females kept in the dark room and those kept under the natural light conditions.

\section{Discussion}

The high rate of dentine apposition in rodent incisors is connected with their constant eruption and intensive wear. Due to these processes, every part of the dentine is steadily shifting peripherally and towards the incisal end, the farther this part shifted the more time elapsed since its formation. For this reason, in the middle of the incisors the hibernation zone was seen in females trapped in March but not in females trapped in June. The eruption rate and the rate of dentine 


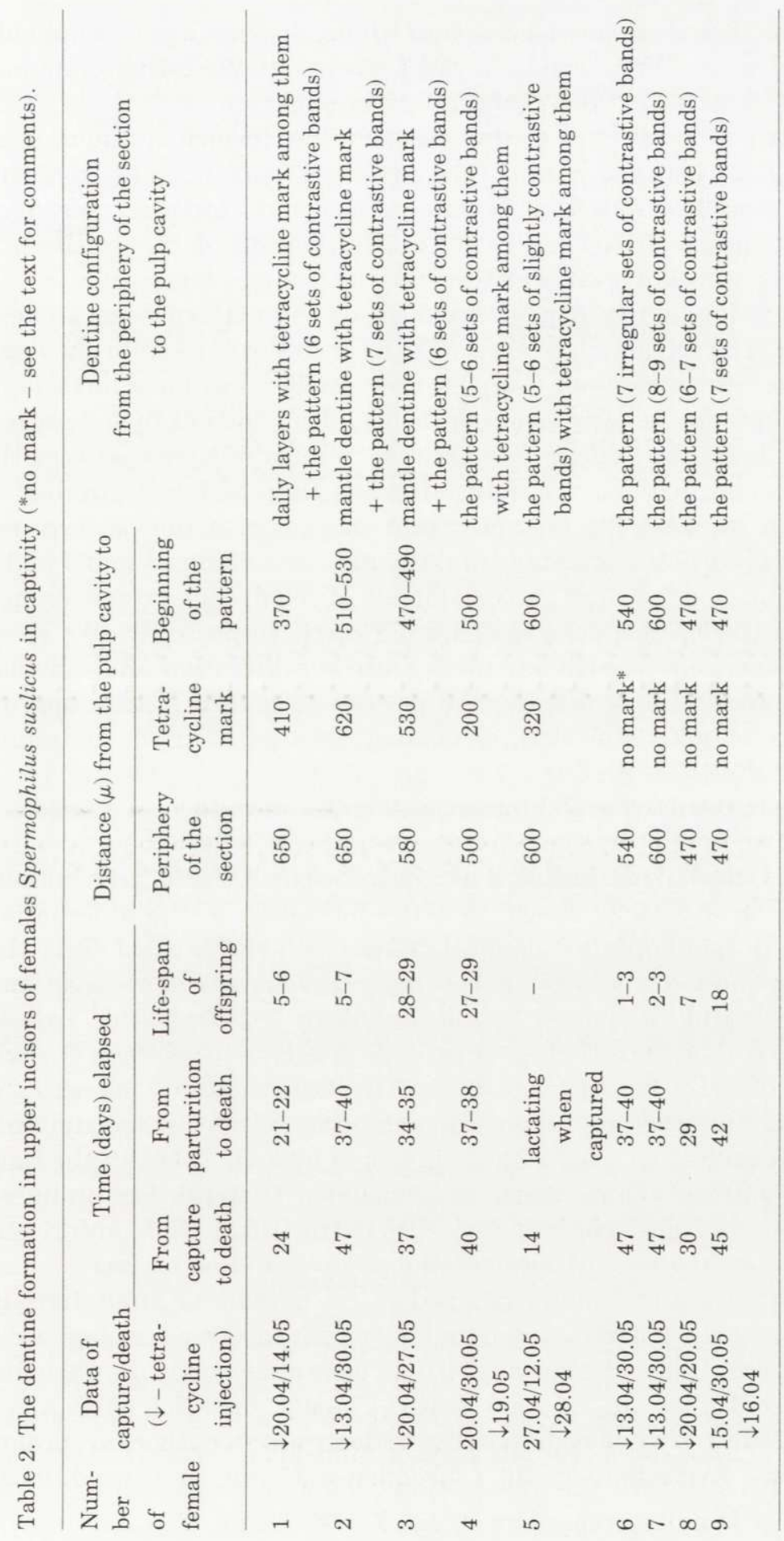


apposition, being species specific as a whole, displays age and individual variations (Klevezal et al. 1990). Owing to these variations the tetracycline mark was found not in all females in 30-47 days after the injection.

In nature, a specific dentine pattern was formed in eight of nine lactating females. It was absent in immature, pregnant, barren, and post-weaning ones. The same pattern was found in all females that gave birth in captivity. Its design is similar to that described previously as lactation zone in the dentine of Spermophilus undulatus and S. pygmaeus (Klevezal and Sukhovskaya 1995).

Tetracycline marked the dentine inside the pattern when it was given during lactation. The tetracycline mark was closer to the pattern in the females that gave birth soon after injection, than in the females that gave birth later. Because of slight expression of daily layers in the lactating females that were kept in captivity during a month we failed to estimate the number of layers between the tetracycline mark and the pattern. To determine the time of the beginning of the pattern formation we used the distance from the mark to the pattern and the rate of dentine apposition calculated from the data of columns 3 and 7 of Table 2. In two females injected 2-3 days and one female injected 7-10 days before parturition, the results were 2.3-4.2 days and 6.8-8.3 days, respectively. We should treat this correspondence as a good one taking into consideration unavoidable errors in the measurements. Consequently, the pattern formation begins approximately with the onset of milk secretion, coinciding with parturition, and continues during lactation.

Similar results were obtained in females in nature. We tried to estimate the length of pregnancy by means of counting the daily layers between the hibernation zone and lactation pattern, as it was proposed by Klevezal and Sukhovskaya (1995). It has been previously shown that the formation of the hibernation zone in the incisors of Spermophilus suslicus ceases with the arousal from the hibernation (Trunova and Lobkov 1997). According to the long-term observations of one of the authors, mating in spotted souslik occurs in 1-2 days after arousal from hibernation; the duration of pregnancy is 24-27 days in average (Lobkov 1995). The number of daily layers formed after the hibernation zone was 24-30 in three individuals just before parturition (embryos of $40 \mathrm{~mm}$ maximum). In five post partum females there were 21-29 layers in average between the hibernation zone and the pattern. Thus, it can be concluded that the beginning of the pattern formation coincides approximately with parturition both in nature and in captivity. Naming it as the parturition-lactation zone would be correct.

In post-weaning females trapped in the middle of June 1989 in nature, the formation of the pattern ceased and only daily layers were observed in dentine. In females in captivity that survived 21-42 days after parturition the formation of the pattern continued up to their death. Usually, lactation lasts about one month (Lobkov 1984). We had no possibility to determine whether this prolonged period of the pattern formation was the consequence of unnatural conditions of captivity. 
There was no correlation between the duration of the pattern formation and the lifespan of the offspring in captivity. The pattern formed in some females during a month after the early death of their offsprings. The selective examination of these females revealed the cessation of milk output from mammal glands after the death of the litter. This shows the lack of a direct connection between the pattern formation and the process of feeding the offspring with milk. Perhaps, the formation of this dentine pattern is caused by a significant change of the level and composition of hormones during parturition-lactation period and not by the mineral metabolism during lactation itself. This means that the presence of lactation zone in dentine indicates the parturition and beginning of lactation and gives no information about the span of the lactation.

It was shown that the endocrinal alterations and nutritional imbalances can be reflected in dentine growth (Schour and Massler 1949, Turnbull et al. 1983, Kuijpers et al. 1996). There is a similarity between the parturition-lactation zone of the sousliks and the changes in dentine microstructure after the parathyroidectomy in rats described by Schour and Massler (1949).

Between-wall variations in contrast of the pattern and in the width of its elements result, obviously, from difference in fine microstructure of the dentine. Labial (covered by enamel) and lingual (covered by cementum) walls of the rodent incisors differ in the rate of apposition, mode of mineralization, and composition of noncollagenous matrix (Beertsen and Niehof 1986, Mishima et al. 1988, 1991, Klevezal et al. 1990, Ohsima and Yoshida 1992).

In one of five barren females from nature, a configuration, similar to that of the parturition-lactation zone, was found in the dentine. However, unlike the parturition-lactation zone, the sets of slightly contrastive bands were single or irregular, separated by the dentine with daily layers and were not so prominent. This configuration looked like the record of short-term torpor states in dentine found in males in spring (Lobkov and Trunova 1998). Probably, barren females can also have short-term hypothermic periods in spring.

We have little information in respect of record of reproductive cycle in the incisor dentine of species other than sousliks. There are some data on records of parturition. Okada and Mimura, as they are cited by Rosenberg and Simmons (1980), found that daily layers slightly stained with hematoxylin (less calcified) were formed in incisor dentine of rabbits just before parturition. The lightly stained bands were found in incisor dentine of 7 out of 9 lactating mice of genus Apodemus; their position in relation to the pulp cavity allowed them to be formed during parturition (Klevezal 1996). The analysis of the upper incisors of ten lactating females of another polyoestrous species - Cricetulus migratorius from the Volgograd region (in two of them birth was exactly dated) was shown that in eight of them, the peculiar contrastive design consisting of hypochromatic band, sandwiched between two hyperchromatic ones was established in such position that it could be considered as the parturition-dependent one (unpubl. data of Y. E. Trunova). Moreover, in seven of them hypo- and hyperchromatic elements of daily 
layers, more contrastive than background ones, were found. The distinctness of these elements varied. Apparently, the record of the phases of a reproductive cycle can be discovered in other species with continuously erupting incisors.

There are data concerning the influence of reproductive cycles on the rate of dentine formation. Miller et al. (1985) and Futatsuki et al. (1995) found that the rate of dentine apposition in incisors increased gradually during pregnancy and decreased immediately after parturition in rats and mice. We found no significant difference in the width of daily layers between barren, pregnant and lactating females, perhaps, due to a small sample size in our case.

\section{References}

Beertsen W. and Niehof A. 1986. Root-analogue versus crown-analogue dentin: a radiograph and ultrastructural investigation of the mouse incisor. Anatomical Record 215: 106-118.

Carvalho R. M., Yoshiyama M., and Pashley E. L. 1996. In vitro study on the dimensional changes of human dentine after demineralization. Archives of Oral Biology 41: 369-377.

Futatsuki T., Matsumoto T. and Nakata M. 1995. Change of dentin formation during the reproductive cycle in mice. Journal of Craniofacial Genetics and Developmental Biology 15: 51-56.

Klevezal G. A. 1996. Recording structures of mammals. Determination of age and reconstruction of life history. Balkema, Rotterdam, Brookfield: 1-274.

Klevezal G. A. and Mina M. V. 1990. Daily layers and hibernation marks in incisor dentin of Sicista pseudonapaea and some biological remarks. Acta Theriologica 35: 345-356.

Klevezal G. A. and Sukhovskaya L. I. 1995. Dentin of incisors of rodents as a recording structure. Zoologicheskiï Zhurnal 74(4): 124-131. [In Russian with English summary]

Klevezal G. A., Pucek M. and Sukhovskaya L. I. 1990. Incisor growth in voles. Acta Theriologica 35: 331-344.

Klevezal G. A., Pucek Z., Sukhovskaya L. I., and Ivanter E. V. 1993. Dentin of incisors of birch mouse, Sicista betulina (Zapodidae, Rodentia) as a recording structure. Zoologicheskiï Zhurnal 72(9): 149-159. [In Russian with English summary]

Kuijpers M. H. M., van de Kooij A. J. and Slootweg P. J. 1996. The rat incisor in toxicologic pathology. Toxicologic Pathology 24, 3: 346-360

Lobkov V. A. 1984. An experience of group marking of young spotted sousliks (Citellus suslicus) with tetracycline for studying their migration. Zoologicheskiï Zhurnal 63(2): 309-312. [In Russian with English summary]

Lobkov V. A. 1995. [Peculiarities of the seasonal phenomena in the life of spotted souslik (Citellus suslicus Guld.) in the northwestern part of the Black Sea area and their ecological consequences]. [In: Research materials of animals (fauna, ecology and theory of researches). V. A. Lobkov, ed]. Nauchnye Trudy Zoologicheskogo Muzeya Odesskogo Gosudarstvennogo Universiteta vol. 2: 33-49. [In Russian]

Lobkov V. A. and Trunova Yu. E. 1998. [The estimation of spring activity of spotted souslik (Spermophilus suslicus) by the analysis of the recording structures]. [In: Diversity of animals researches. V. A. Lobkov, ed]. Nauchnye Trudy Zoologicheskogo Muzeya Odesskogo Gosudarstvennogo Universiteta vol. 3: 69-75. [In Russian]

Miller S. C., Omura T. H. and Smith L. J. 1985. Changes in dentin appositional rates during pregnancy and lactation in rats. Journal of Dental Research 64: 1062-1064.

Mishima H., Sakae T., Kozawa Y., and Hirai G. 1988. Structural variation in labial and lingual dentin in rat incisor. Journal of Nihon University School of Dentistry 30: 1-10. 
Mishima H., Kozawa Y. and Sakae T. 1991. Two patterns of calcification in rat and rabbit incisor dentin. [In: Mechanisms and phylogeny of mineralization in biological systems. S. Suga and H. Nakahara, eds]. Springer-Verlag, Tokyo: 223-227.

Ohshima H. and Yoshida S. 1992. The relationship between odontoblasts and pulp capillaries in the process of enamel- and cementum-related dentin formation in rat incisors. Cell and Tissue Research 268: 51-63.

Ohtsuka M. and Shinoda H. 1995. Ontogeny of circadian dentinogenesis in the rat incisor. Archives of Oral Biology 40: 481-485.

Rosenberg G. D. and Simmons D. J. 1980. Rhythmic dentinogenesis in the rabbit incisors: circadian, ultradian and infradian periods. Calcified Tissue International 32: 29-44.

Schour I. and Massler M. 1949. The teeth. [In: The rat in laboratory investigation, J. Q. Griffith and E. J. Farris, eds]. J. B. Lippincott Co. L. Montr.: 104-165.

Schour I. and Steadman S. R. 1935. The growth pattern and daily rhythm for the incisor of the rat. Anatomical Record 63: 325-333.

Trunova Yu. E. and Lobkov V. A. 1997. Recording the hibernation peculiarities by incisor dentin in spotted souslik Spermophilus suslicus (Sciuridae, Rodentia). Russian Journal of Zoology 1(3): 352-359.

Turnbull R. S., Heersche J. N., Tam C. S. and Howley T. P. 1983. Parathyroid hormone stimulated dentin and bone apposition in the thyroparathyroidectomized rat in a dose-dependent fashion. Calcified Tissue International 35: 586-590.

Received 17 November 1997, accepted 12 November 1998. 